\title{
Os primeiros passos na carreira docente: um estudo com professores moçambicanos
}

\author{
Geraldo Vernijo Deixa \\ Universidade Licungo - UniLicungo, Moçambique \\ Rosalino Subtil Chicote \\ Universidade Rovuma - UniRovuma, Moçambique \\ Sidónio Francisco Calisto \\ Escola Secundária Geral 25 de Junho Lua-Lua, Moçambique
}

\section{RESUMO}

O artigo caracteriza o processo de inserção na carreira docente de professores moçambicanos. Assim, colocamos a seguinte questão: que traços evidenciam o processo de inserção na carreira docente no contexto moçambicano? Foi aplicado um questionário a 29 professores do Ensino Básico da cidade de Quelimane. Os resultados obtidos revelam que a carreira docente é uma profissão complexa que exige uma colaboração e sensibilização dos gestores. A fraca colaboração em nível institucional coloca em risco a construção da identidade do professor.

PALAVRAS-CHAVE: Desenvolvimento Professional. Trabalho Colaborativo. Início da Carreira.

\section{THE FIRST STEPS IN THE TEACHING CAREER: A STUDY WITH MOZAMBICAN TEACHERS}

\begin{abstract}
The article characterizes the process of insertion in the teaching career of Mozambican teachers. Thus, the following question was raised: What features highlight the process of insertion in the teaching career in the Mozambican context? A questionnaire was applied to 29 teachers of Basic Education in the city of Quelimane. The results obtained reveal that the teaching career is a complex profession that requires collaboration and awareness from managers. The weak collaboration at institutional level puts at risk the construction of the identity of the teacher.
\end{abstract}

KEYWORDS: Professional Development. Collaborative Work. Beginning of the Career

\section{LOS PRIMEROS PASOS EN LA CARRERA DOCENTE: UN ESTUDIO CON MAESTROS MOZAMBIQUEÑOS}

\section{RESUMEN}

El artículo caracteriza el proceso de inserción en la carrera docente de los maestros mozambiqueños. Así pues, se planteó la siguiente pregunta: ¿Qué características destacan el proceso de inserción en la carrera docente en el contexto mozambiqueño? Se aplicó un 
cuestionario a 29 maestros de escuela primaria de la ciudad de Quelimane. Los resultados obtenidos revelan que la carrera docente es una profesión compleja que requiere la colaboración y la sensibilización de los directivos. La débil colaboración a nivel institucional pone en peligro la construcción de la identidad del maestro.

PALABRAS-CLAVE: Desarrollo Profesional. Trabajo en Colaboración. Comienzo de la Carrera.

\section{INTRODUÇÃO}

Em Moçambique, a formação de professores para diferentes subsistemas de Educação é assegurada pelas Instituições de Formação de Professores. Para o Ensino Primário, ela é assegurada pelos Institutos de Formação de Professores (IFP) e Ajuda do Povo para o Povo (ADPP). A formação de professores para o Ensino Secundário é de responsabilidade das universidades públicas e privadas bem como dos Institutos de Educação Aberta e a Distância (EaD). Em sua maioria, essas instituições formam professores de diferentes áreas.

Após sua formação, a instituição formadora não faz acompanhamento desses para perceber o desenvolvimento das suas atividades na prática. Esse fato faz com que o professor novato trabalhe muitas vezes isolado, quase sem apoio quer da instituição onde se encontra inserido, quer dos demais colegas experientes. Diferentemente do que acontece na área de saúde, os médicos têm tido acompanhamento nos primeiros anos de serviço. Aliás, o trabalho cooperativo e colaborativo é mais evidente nessa área. Assim, no início da carreira, o professor moçambicano enfrenta várias dificuldades de inserção, por exemplo, falta-lhe tudo, desde alimentação, habitação até apoio material e moral.

Pensamos que não existe uma formação perfeita que pode assegurar um ensino de tudo. Aliás, pode até ensinar tudo o que o futuro professor necessita para o exercício de suas atividades, mas essa não é uma garantia de que realmente ele tenha aprendido tudo. Nesse sentido, admitimos que a aprendizagem é um processo permanente devido à complexidade do saber docente. Portanto, este é incompleto (TARDIF, 2012). Por essa razão, necessita sempre ser complementado.

Assim, levantamos a seguinte indagação: que traços evidenciam o processo de inserção na carreira docente no contexto moçambicano? O objetivo da pesquisa foi caracterizar o processo de inserção na carreira docente de professores moçambicanos. Para coadjuvar a questão orientadora, levantamos as seguintes questões complementares de pesquisa: como ocorre o processo de inserção de professores em início de carreira nos primeiros 3 anos? Como professores em início de carreira superam as dificuldades que enfrentam para sobrevivência? 


\section{REVISÃO DE LITERATURA}

Huberman tem sido uma das referências em estudos sobre a carreira docente. Ele afirma que os primeiros três anos de carreira são decisivos para a continuidade nessa ou o abandono dela. Nesse período, o professor experimenta o momento de choque de realidade, sentimentos de sobrevivência e de descoberta. Estas permitirão a continuidade na carreira. Nesse período ocorrem tensões, dificuldades, desafios, mas também intensas aprendizagens (HUBERMAN,1989).

Ele distingue cinco fases que marcam o processo de evolução da profissão docente nomeadamente: a entrada na carreira (de 1 a 3 anos), a estabilização (de 4 a 6 anos), a experimentação ou diversificação (de 7 a 25 anos) e a preparação para a aposentadoria (de 35 a 40 anos). No Quadro 1, indicamos as principais características de cada fase.

Quadro 1 - Fases da evolução da profissão docente

\begin{tabular}{|c|c|}
\hline Fases & Características \\
\hline 1. A entrada na carreira & $\begin{array}{l}\text { - Exploração (investigação, dificuldades, insegurança, improviso, } \\
\text { entusiasmo inicial, fracasso, socialização na profissão e busca de } \\
\text { alternativas para superação de dificuldades). } \\
\text { - Sobrevivência. } \\
\text { - Choque de realidade. } \\
\text { - Descoberta. } \\
\text { - De } 1 \text { a } 3 \text { anos de profissão. }\end{array}$ \\
\hline 2. Estabilização & $\begin{array}{l}\text { - Transição para o profissionalismo. } \\
\text { - Identidade profissional. } \\
\text { - Emancipação ou libertação, autonomia do professor. } \\
\text { - Preocupa-se com o ensino e a aprendizagem dos alunos. } \\
\text { - Flexibilidade, humor e prazer do professor. } \\
\text { - De } 4 \text { a } 6 \text { anos de profissão. }\end{array}$ \\
\hline $\begin{array}{l}\text { 3. Diversificação e } \\
\text { experimentação }\end{array}$ & $\begin{array}{l}\text { - Competências profissionais. } \\
\text { - Autoridade, responsabilidade e prestígio. } \\
\text { - Busca de novos desafios. } \\
\text { - De } 7 \text { a } 25 \text { anos de profissão. }\end{array}$ \\
\hline 4. Serenidade & $\begin{array}{l}\text { - Atitude de serenidade e distanciamento afetivo ou de } \\
\text { conservadorismo e lamentações. } \\
\text { - De } 25 \text { a } 35 \text { anos de profissão. }\end{array}$ \\
\hline 5. Desinvestimento & $\begin{array}{l}\text { - Preparação para a aposentadoria e progressivo abandono das } \\
\text { responsabilidades profissionais. } \\
\text { - De } 35 \text { a } 40 \text { anos de profissão. }\end{array}$ \\
\hline
\end{tabular}

Fonte: elaborado pelos autores a partir de Huberman (1989).

Geralmente, o professor inicia a carreira docente com uma visão diferente de um professor experiente. Assim, nos primeiros três anos, por mais favorável a sua preparação psicopedagógica, didática e científica, existe sempre o chamado "choque de realidade" (SILVA, 
1997, p. 53). Diante dessa situação, o docente procura alternativas para a sobrevivência na carreira, podendo nesse momento ocorrer uma descoberta que o deixa confortável como também um acontecimento que o leva a abandonar a carreira.

Pacheco e Flores (1999) reconhecem que diferentemente do que se verifica em outras profissões a entrada na carreira docente é brusca e repentina, tendo o professor iniciante que desempenhar as mesmas tarefas e assumir as mesmas funções de um professor experiente. Corroboramos Couto (1998, p.90) quando este se refere que ao entrar no mundo profissional o professor abandona alguma segurança formada por meio de apoios sucessivos, ele tem que decidir sozinho e encarar desafios que o obrigam a crescer. Desse modo, entendemos que a entrada do professor novato no mundo de trabalho é sempre difícil, pois a transição de formando para professor por vezes está sujeita a alterações devido ao modo de vida individual e coletivo. Jesus e Santos (2004, p.42) atestam que o professor nos primeiros anos de serviço experimenta papéis e avalia a sua competência profissional. Dessa tentativa pode resultar três configurações: sobrevivência, se o confronto com a realidade escolar tiver sido problemático, pela ocorrência de fracassos na dinâmica criada nos processos de ensino e de aprendizagem; descoberta, se for experienciado sucesso, entusiasmo e satisfação com as novas experiências; indiferença, se o professor escolheu a profissão docente por falta de outras alternativas profissionais.

Como refere Cavaco (1993, p.114), os primeiros anos evidenciam marcas profundas na maneira como se pratica a profissão. Além disso, o período inicial da carreira é fundamental porque um fracasso nessa fase leva frequentemente à desvalorização pessoal, enquanto o mesmo fracasso ocorrido alguns anos mais tarde será, provavelmente, apenas vivenciado como uma mera exceção.

Nos primeiros três anos de carreira, os professores iniciantes atravessam um período árduo, ao longo do qual procuram aprender por meio da prática do trabalho docente e comparam os conhecimentos adquiridos durante a formação nas instituições de formação de professores de distintos níveis de ensino com as possibilidades oferecidas pelo campo de trabalho. Por um lado, têm necessidade de ajustar-se e integrar-se ao grupo do qual sugerem fazer parte de modo a construir suas próprias percepções e identidades como profissionais docentes. Esse processo é promovido e potencializado pela dificuldade enfrentada ao se defrontarem com um cenário complexo (PONTE et al., 2001).

Esses cenários complexos os levam a criar grupos de colaboração constituídos por colegas e amigos e a pertencê-los. Eles são criados com base em amizade ou naturalidade dos envolvidos. No entanto, com apoio de professores experientes, membros de direção, alunos, 
família, comunidade e as Zona de Influência Pedagógica (ZIP), algumas destas dificuldades são ultrapassadas (DEIXA, CHICOTE e GONÇALVES, 2020).

De acordo com Nóvoa (1995), o sentimento de sobrevivência ocorre no manuseamento do que tem sido chamado de "choque do real", advindo do confronto inicial com a complexidade da situação profissional. Concernente a essa fase, decorre o tateamento e a preocupação (dúvida ou incerteza), com a administração da distância entre o imaginário e o concreto na sala de aula, a necessidade de responder aos desafios e simultaneamente à relação com o meio escolar e à materialização dos conteúdos, a dúvida entre as oscilações nas relações (com os alunos), as dificuldades com os alunos que criam problemas e com o material didático impróprio e a incerteza em relação à metodologia.

O sentimento de descoberta ocorre no momento de entusiasmo inicial, a exaltação por sentir-se integrante de um corpo profissional, por estar, finalmente, em uma situação de responsabilidade, por sentir-se incorporado ao mundo adulto e pela satisfação que representa a exploração de um novo marco social que representa a escola para o professor novato (Ibidem, 1995).

Como refere Silva (1997, p.54), o choque de realidade manifesta-se em cinco indicadores: percepção dos problemas, mudanças de comportamento, de atitude e de personalidade e autoconceito e abandono da profissão. Para minimizar os efeitos desses indicadores, há necessidade de um apoio contínuo das escolas e dos professores experientes. Nóvoa (2001, p.13) explica que as práticas de formação continuada devem ter como núcleo de referência as escolas. São estas e os professores dispostos nelas que podem determinar quais são os melhores meios, os melhores métodos e as melhores formas de garantir a formação continuada. Essa colaboração deve contar com especialistas universitários. Assim, a lógica de formação continuada deve ser centrada nas escolas e numa organização dos próprios professores (grupos colaborativos) para assegurar o seu progresso profissional.

Essa lógica de formação continuada do professor justifica a necessidade de crescimento e de aquisições diversas. Nesse processo se atribui ao próprio professor o papel de sujeito fundamental (PONTE, 1994, p.10). Nesse sentido, percebe-se que o Desenvolvimento Profissional (DP) é sobretudo de responsabilidade individual.

O DP pode ser potencializado por meio de ações de formação, participação em eventos científicos da área, produção e publicação de artigos em revistas especializadas, entre outras ações. Nestes eventos, os professores podem discutir assuntos que os afligem.

Na perspectiva de Garcia (2009, p.7), o desenvolvimento profissional do professor implica a busca da sua identidade profissional, a forma como ele define a si mesmo e o outro. 
Assim, percebe-se que o desenvolvimento profissional é refletido num conjunto de atividades, práticas e ações de docência que determinam a profissionalização do professor novato.

Tardif (2012) considera o saber experiencial como um dos saberes fundamentais para o desenvolvimento profissional do professor. O autor explica que o processo de construção do eu profissional ocorre no dia a dia no local de trabalho por meio de vivências, experiências aprendidas com colegas e atividades extracurriculares ao longo da carreira docente.

Para Garcia (1999), os professores obtêm conhecimentos, habilidades e atitudes nesse período, mas pouco se sabe sobre suas ações educativas e sua adaptação à profissão. Destaca ainda que é preciso atender os professores iniciantes não só como uma demanda social, mas também como uma exigência de justiça social, visando assegurar o melhor ensino possível. E conclui afirmando que se desejarmos avançar na qualidade do ensino - -aprendizagem- e nos resultados escolares dos alunos, há de se refletir acerca dos princípios de desenvolvimento profissional, bem como dos apoios e da promoção de bem-estar docente aos iniciantes.

Entendemos que a carreira é igualmente um processo de socialização, isto é, um processo de marcação e de incorporação dos indivíduos às práticas e rotinas oficializadas das equipes de trabalho. Estas exigem que os indivíduos se apropriem dessas práticas e rotinas, e não o inverso (TARDIF, 2012).

\section{METODOLOGIA}

Elaboramos um questionário constituído por 8 questões abertas cujo objetivo foi compreender os processos de inserção na carreira docente. Para tal, foi estabelecido um contato entre a equipe da pesquisa e as direções das duas escolas primárias da cidade de Quelimane. Por meio desses contatos, obtivemos autorização para desenvolver a coleta de dados. Marcamos uma reunião com professores e explicamos que o grupo-alvo eram professores do Ensino Primário. Foram explicados os objetivos da pesquisa e salientamos que a participação era voluntária. Orientamos também que, após o preenchimento, os questionários deveriam ser entregues às direções das respectivas escolas.

Retornamos às escolas depois de uma semana e mantivemos contato com as direções para proceder a recolha dos questionários. Neste segmento, foram considerados como participantes da pesquisa 29 professores que responderam integralmente ao questionário. A idade mínima dos participantes foi de 18 anos.

O processo de análise de dados consistiu em dois momentos: primeiro, leitura do material com objetivo de captar frequências e tendências das respostas e segundo leitura realizada com o objetivo de captar temas nas respostas. Isso permitiu agregar respostas em 
unidades de registros, que foram apresentados em quadros ou tabelas. Assim desenvolvemos categorias emergentes, ou seja, aquelas que surgem a partir da leitura dos dados. A análise dos dados foi realizada à luz da Análise Textual Discursiva (MORAES; GALLIAZZI, 2011).

\section{ANÁLISE E INTERPRETAÇÃO DE DADOS}

Nessa seção apresentamos e discutimos os dados que resultam do questionário aplicado aos professores. A apresentação e a discussão seguem a sequência das questões aplicadas. Assim, apresentamos a questão e, em seguida, a sua descrição e seus comentários.

Na sequência, apresentamos os dados da primeira questão: que dificuldades tiveram nos primeiros três anos de lecionação? O quadro abaixo expõe os resultados.

Quadro 2 - Síntese das respostas dos inquiridos

\begin{tabular}{|l|l|}
\hline Fonte das dificuldades & Dificuldades \\
\hline Pessoal & $\begin{array}{l}\text { Insegurança ao lidar com alunos. } \\
\text { Fraqueza acerca de estabelecer um ambiente de comunicação com } \\
\text { alunos. }\end{array}$ \\
\hline Profissional & $\begin{array}{l}\text { Inflexibilidade no relacionamento com colegas e comunidade. } \\
\text { Instabilidade na planificação de aulas. } \\
\text { Deficiência no conhecimento didático. }\end{array}$ \\
\hline Institucional & Falta de material didático. \\
\hline
\end{tabular}

Fonte: Dados da pesquisa, 2020.

Conforme o Quadro 2, as dificuldades de âmbito pessoal gravitam em torno das inseguranças em lidar com alunos. Esse fato consta nos traços expostos por Huberman (2000). Todavia as dificuldades de âmbito profissional registraram maior incidência. Tudo indica que a profissão docente encerra complexidades. À luz desse ponto, o professor está longe de ser um profissional acabado e amadurecido depois que recebe a sua habilitação profissional (PONTE apud DEIXA, CHICOTE e GONÇALVES, 2020, p.153).

A falta de material didático também constituiu um dos aspectos mais mencionados. Conforme assegura AFRIMAP e OSISA (2012), as escolas moçambicanas enfrentam o problema de falta de material didático, o que influencia a baixa qualidade da educação. Apesar de o relatório ter sido publicado em 2012, os resultados dessa pesquisa revelam que o problema ainda prevalece.

Em relação à questão 2: como ultrapassou essas dificuldades?

O Quadro 3 mostra as fontes de influências que ajudaram a minimizar as dificuldades destes professores em início da carreira. 
Quadro 3 - Mecanismo para superação de dificuldades

\begin{tabular}{|l|l|}
\hline Fontes de influência & Formas utilizadas para ultrapassar dificuldades \\
\hline Pessoal & Acesso a determinadas fontes de conhecimentos, como livros e outros. \\
\hline Profissional & $\begin{array}{l}\text { Colaboração com colegas, direção e comunidade. } \\
\text { Participação em capacitações e atividades de grupos de disciplinas. }\end{array}$ \\
\hline
\end{tabular}

Fonte: Dados da pesquisa, 2020.

Das respostas dos inquiridos, 3 dos 29 procuraram desenvolver-se profissionalmente por iniciativa própria, individualmente, recorrendo a fontes de conhecimentos. Essa preocupação está relacionada aos pressupostos de Shulman (2014) sobre fontes para a base de conhecimento para o ensino.

Ainda o Quadro 2 revela que a fonte de influência privilegiada para superação das dificuldades tem sido os colegas. Deixa, Chicote e Gonçalves (2020) numa pesquisa realizada com 10 professores do Ensino Primário do distrito de Namacurra revelam que os processos de desenvolvimento profissional dos professores em início de carreira circunscrevem-se aos processos de colaboração embora com fraca participação.

Alguns inquiridos referem que "[...] o tempo foi fundamental para ultrapassar as dificuldades [...]". Esse posicionamento foi expresso por 4 dos 29 inquiridos. No tocante ao tempo, Tardif e Raymond (2000) sustentam que o tempo de serviço transforma o professor e a forma de exercer sua profissão.

$\mathrm{Na}$ terceira pergunta, interrogados sobre o apoio que a escola lhes ofereceu nos primeiros três anos de carreira, os inquiridos mencionaram que a instituição tem promovido ações que os ajudam a superar dificuldades, tais como: apoio moral para permanecer na carreira (6 dos 29 inquiridos), fornecimento de material didático (12 dos 29 inquiridos) e 5 dos 29 inquiridos referem-se à promoção de ações de capacitação.

Porém, há uma discordância em termos de eficiência do apoio fornecido pela escola. Os dados indicam que 10 dos 29 sujeitos inquiridos julgam que o apoio não foi suficiente. Contrariamente, a maioria considera que a escola apoiou seu desenvolvimento profissional em certa medida. 
Quadro 4 - Como docente durante estes três anos em que momento se sentiu à vontade?

\begin{tabular}{|l|l|c|}
\hline Categorias & Momento em que me senti à vontade & Frequência \\
\hline Tempo como fonte & $\begin{array}{l}\text { Antes de dois anos de serviço. } \\
\text { Depois de dois anos de serviço. }\end{array}$ & 2 \\
\hline Ações como fonte & $\begin{array}{l}\text { Atos administrativos (nomeação definitiva). } \\
\text { Mediante parecer do pedagógico sobre uma aula assistida. } \\
\text { Experiência proveniente da prática letiva. }\end{array}$ & 7 \\
\hline
\end{tabular}

Fonte: Dados da pesquisa, 2020.

Em relação à análise do Quadro 4, percebemos que o professor principiante começa a se sentir à vontade a partir de dois fatos: tempo de magistério e ações que exerce. Nos primeiros anos de serviço, o professor busca dominar a profissão por meio de recurso quanto à prática letiva, a assistências mútuas e a pareceres da direção pedagógica sobre o desempenho qualitativo e quantitativo. A motivação aumenta ainda quando o professor se sente efetivo na carreira, ou seja, quando é nomeado definitivamente. O Quadro 3 esclarece ainda que as ações dos professores nos primeiros três anos são a fonte para a sobrevivência na carreira.

P5: Esse apoio foi suficiente para superar as dificuldades enfrentadas?

Em relação à essa questão, verificamos que 19 dos 29 inquiridos consideram que o apoio dado foi suficiente para superar as suas dificuldades e 10 dos 29 indicam que tal apoio não tem sido suficiente para superar os problemas que enfrentam em relação aos alunos.

Perguntados sobre: Que aspecto pode avançar para melhorar o momento de inserção na carreira nos primeiros três anos?, as respostas foram as da Tabela 1.

Tabela 1 - Aspecto para melhorar o momento de inserção na carreira

\begin{tabular}{l|c}
\hline Aspecto para melhorar o momento de inserção & Frequência absoluta \\
\hline Material didático & 5 \\
\hline Seminários de capacitação & 5 \\
\hline Grupos de colaboração com professores experientes & 10 \\
\hline Aspectos organizacionais & 2 \\
\hline Humildade acadêmica & 6 \\
\hline Total & 28 \\
\hline
\end{tabular}

Fonte: Dados da pesquisa, 2020.

$\mathrm{O}$ dado do quadro anterior elucida que o maior fator para melhorar o momento de inserção do professor no início de carreira circunscreve-se em colaboração com grupos de professores experientes (10 dos 29 inquiridos). Esse processo requer humildade acadêmica por 
DEIXA, G. V.; CHICOTE, R. S.; CALISTO, S. F.

parte dos professores principiantes ( 6 dos 29 inquiridos). A disponibilidade do material didático para professores e a realização de seminários periódicos configuram como ações fundamentais para a inserção na carreira. Outro aspecto apontado pelos inquiridos (2 dos 29) refere-se à necessidade de o professor estar preparado para atender a classe. Isso passa pela preparação prévia dos conteúdos a serem lecionados.

Sobre a questão: Já pensou alguma vez em mudar de profissão? Por quê?, os resultados encontram-se na Tabela 2.

Tabela 2 - Desânimo com a profissão

\begin{tabular}{l|c}
\hline Unidades de registros & Frequência absoluta \\
\hline Mudança da profissão & 4 \\
\hline Permanência na profissão & 25 \\
\hline
\end{tabular}

Fonte: Dados da pesquisa, 2020.

Os dados da Tabela 2 apontam que 4 dos 29 inquiridos preferem a mudança de profissão com vista à melhoria de vida. Essa se justifica ainda pelas péssimas condições de trabalho que o setor enfrenta e pela necessidade de ganhar novas experiências em outras áreas. No entanto, a maioria, 25 dos 29 inquiridos, prefere permanecer na carreira, o que é justificado pelas seguintes razões: sonho em relação à profissão, desejo de ensinar e aprender, amor à profissão e segurança/garantia de emprego.

Aos participantes foi perguntado: Como avalia os seus primeiros três anos de carreira como professor em termos de colaboração?

Quadro 5 - Avaliação dos primeiros 3 anos em termos de colaboração

\begin{tabular}{|l|l|c|}
\hline Avaliação & Aspectos característicos & Frequência absoluta \\
\hline Fator positivo & Colaboração entre pares & 16 \\
\hline Fator negativo & Ausência de colaboração & 5 \\
\hline Total & & 21 \\
\hline
\end{tabular}

Fonte: Dados da pesquisa, 2020.

O Quadro 5 evidencia que os primeiros três anos de carreira foram marcados pela colaboração entre professor e direção da escola (16 dos 29 inquiridos). Apesar dessa colaboração, outro grupo enfrentou vários desafios para a superação de dificuldades encontradas (5 dos 29). Por exemplo, o inquirido P 21 avalia os primeiros três anos de forma 
negativa: "Porque senti que os esforços feitos tanto pela escola assim como pelo professor no âmbito de colaboração foram deficientes".

\section{CONSIDERAÇÕES FINAIS}

O início de qualquer carreira é sempre caracterizado por medo, insegurança, incertezas, entre outros aspectos. Nesse sentido, um apoio é insubstituível, principalmente para a carreira docente, pelo fato de o professor lidar diretamente com pessoas em torno de um saber. É este que une o docente e o aluno, estabelecendo uma situação didática. Para o crescimento deste profissional, há necessidade de investimento pessoal ou coletivo.

Os inquiridos reconhecem o que fazer para melhorar a sua inserção na carreira docente, no entanto falta colaboração instituída por dispositivos legais da escola. Cada professor busca um modo de como se desenvolver profissionalmente para garantir a sobrevivência na carreira. A pesquisa revelou ainda que a ação externa constitui alternativa para a consolidação da carreira. A inserção do professor na carreira docente é problemática. Isso pode prejudicar a constituição da identidade profissional.

No contexto moçambicano, são quase inexistentes as pesquisas sobre o ciclo de vida profissional do professor, daí a necessidade de mais investigações nessa área. Outro aspecto que precisa ser investigado são os ciclos da vida profissional do professor ajustada à realidade moçambicana, dado que os anos de serviços para aposentadoria são 35, o que difere do modelo proposto por Huberman, até 40 anos.

\section{REFERÊNCIAS}

AFRIMAP; SOISA. A prestação efectiva de serviços públicos no sector da educação. Um relatório publicado pelo AfriMAP e pela Opens Soceity Initiative for Southern Africa, 2012.

CAVACO, Maria Helena. Ofício do professor: o tempo e as mudanças. Porto: Porto Editora, 1993.

COUTO, Cecília Galvão. Professor: o início da prática profissional. Lisboa: Faculdade de Ciências da Universidade de Lisboa.1998.

DEIXA, Geraldo Vernijo; CHICOTE, Rosalino Subtil; GONÇALVES, Elsa. A influência da indução de professores principiantes na qualidade de ensino no $1^{\circ}$ grau do ensino básico em Moçambique. Formação Docente. Belo Horizonte. Vol. 12, no. 24 (p. 151-164) 31 ago. 2020. Disponível em: https://revformacaodocente.com.br/index.php/rbpfp/article/view/281. Acesso em 13 dez. 2020. 
GARCÍA, Carlos Marcelo. Desenvolvimento profissional docente: passado e futuro. Sísifo: Revista de Ciências da Educação, Lisboa, no. 8, jan./abr. 2009. Disponível em: http://www.unitau.br/files/arquivos/category_1/MARCELO Desenvolvimento_Profissiona 1_Docente_passado_e_futuro_1386180263.pdf. Acesso em 13 dez. 2020.

GARCÍA, Carlos Marcelo. Formação de Professores: para uma mudança educativa. Porto: Porto editora, 1999.

HUBERMAN, Michael. Ciclo de vida profissional do ensino médio. Genebra: Universidade de Genebra, 1989.

JESUS, Saul Neves de; SANTOS, Jonas Conduto Vieira. Desenvolvimento profissional e motivação dos professores. Porto Alegre, RS, 2004.

MORAES, Roque; GALIAZZI, Maria do Carmo. Análise textual discursiva. 2. ed. - Ijuí, RS: Editora Unijuí, 2011.

NÓVOA, António. Vida de Professores. 2.ed. Lisboa: Porto Editora. 1995.

PACHECO, José Augusto; FLORES, Maria Assunção. Formação e avaliação de professores. Porto: Porto Editora. 1999.

PONTE, João Pedro da. O desenvolvimento profissional do professor de matemática. Educação e Matemática. Lisboa: SEM-SPCE, 1994.

PONTE, João Pedro da. et al.. O início da carreira profissional de professores de matemática e ciências. São Paulo, Revista de Educação, 2001.

SHULMAN, Lee. Conhecimento e ensino: fundamentos para a nova reforma. Cadernos Cenpec, São Paulo, v.4, n.2, p.196-229, dez. 2014. Disponível em: http://cadernos.cenpec.org.br/cadernos/index.php/cadernos/article/view/293. Acesso em 13 dez. 2020.

TARDIF, Maurice. O primeiro ano de docência: o choque com a realidade. Porto: Porto Editora. 1997.

TARDIF, Maurice. Saberes docentes e formação profissional. 14 ed., Rio de Janeiro: Vozes, 2012.

TARDIF, Maurice; RAYMOND, Danielle. Saberes, tempo e aprendizagem do trabalho no magistério. Educação \& Sociedade, Campinas, v.21, n.73, p.209-244. 2000. Disponível em: https://www.scielo.br/pdf/es/v21n73/4214. Acesso em 13 dez. 2020.

\section{SOBRE OS AUTORES}

Geraldo Vernijo Deixa é Doutor em Ensino de Ciências e Educação Matemática e Professor Associado da Universidade Licungo, Moçambique, África.

E-mail: gdeixa@unilicungo.ac.mz

ORCID: https://orcid.org/0000-0002-3992-0993 
Rosalino Subtil Chicote é Professor da Universidade Rovum e Mestrando em Educação e Currículo na mesma universidade, Moçambique, África.

E-mail: rchicote@unirovuma.ac.mz

ORCID: https://orcid.org/0000-0003-3454-7816

Sidónio Francisco Calisto é Licenciado em Ensino de Matemática, Metrando em Educação e Currículo, Professor de Matemática da Escola Secundária Geral 25 de Junho Lua-Lua, Moçambique, África.

E-mail: sidoniocalisto2@gmail.com

ORCID: https://orcid.org/0000-0001-6699-0383 